\title{
The Prediction of Job Satisfaction Based on Coping Skills in Pilots and Assistant of Pilots
}

\author{
Fereshteh Kohantorabi, Khadijeh Abolmaali* \\ Department of Psychology, Roudehen Branch, Islamic Azad University, Roudehen, Iran \\ Email: 'Sama.Abolmaali@gmail.com
}

Received 19 April 2014; revised 16 May 2014; accepted 12 June 2014

Copyright (C 2014 by authors and Scientific Research Publishing Inc.

This work is licensed under the Creative Commons Attribution International License (CC BY). http://creativecommons.org/licenses/by/4.0/

(c) (i) Open Access

\begin{abstract}
The purpose of this research was to predict job satisfaction among pilots and assistant based on coping skills. Two hundred pilots and assistant were randomly selected from Mehrabad airport. They completed job satisfaction and skills coping questionnaires. Multiple regression test was used to analyze the data. The results showed that coping skills can predict job satisfaction, in other words it can be said that only the somatization component, emotional inhibition of the coping skills could predict job satisfaction of pilots and assistant.
\end{abstract}

\section{Keywords}

Job Satisfaction, Coping Skills

\section{Introduction}

The job satisfaction is subjected to represent the feelings as well as positive attitudes towards someone's occupation [1] and it can be also considered as the affective adaptation with occupation and occupational circumstances [2]. The job satisfaction can make confidence and loyalty towards an organization. It cannot be the resulting from the only simple encouragement of staffs [3]. Stress has been defined as "the state manifested by the specific syndrome, which consists of all the non-specific induced changes in a biological system" [4]. Stress affects the individual's well-being, both physically and emotionally. It seems that the ability to successfully cope with stress can lead to a reduction in disappointment and anxiety [5]. Research results show that some of stressors relating to pilots and flight personnel in Iran include aging equipment and machinery, limited rest periods, work-related errors, fear of the possibility of an air accident, and fatigue due to excessive flight shifts [6]. Ineffective coping with stress may affect physical and cognitive function sand increase the risk of accidents due to human error. Therefore, a study of the relationship between coping skills and job satisfaction is very important.

\footnotetext{
"Corresponding author.
} 
The job satisfactions subjected to the pleasant satisfaction meeting the basic requirements at work and the effectiveness of the functional affairs [7] [8]. Herzberg defines two dimensions for the process of job satisfaction. The first dimension includes the occupational features such as the peer rights, interpersonal communication and work conditions; the second one is related to the motivational factors regarding the importance of progression, reputation, responsibility and growth [9]. The whole organizations tend to persuade their staffs' job satisfaction. When these staffs are satisfied of their occupation, they will be more creative giving suggestions in order to the progression case. The lack of job satisfaction leads to the low commitment level preventing an organization to reach to the most suitable function in this regard. An employer having high satisfaction will have low reluctance along with low stress leading to the increase of profitability and productivity [10].

When the effective coping skills are increased, the job stress will be reduced. Coping skills and organizational commitment are two important predictors of job satisfaction [11]. The job satisfaction increases employee motivation, and motivation is an important factor of the behavior having a relationship with the job performance, because the motivation provokes the energies and increases work efficiency in this pavement satisfying the staffs [12]. In many researches it is shown that the job satisfaction and job stress have close relationship together and if the job satisfaction is increasing, the job stress will be reducing in this case [13]-[16]. The stress can influence on the mental health, the job satisfaction also is being affected by the same stress [17] [18]. Some stressors being paid attention in job situations are as following:

Some typical job stressors seen in the work environment—such as time sensitive project deadlines and limited times for ending the plans up, office politics, insincere/negative managers, important job presentations and meetings — can produce similar physiological and psychological responses to that experienced by war veterans' responses to combat "stress" [19]. Many researchers have found the negative relationship between the job stressses and coping skills; social support can be an important mediator for the job stress and job satisfaction [20]. Some of studies showed that about $75 \%$ of the flight accidents regarding to the human agents; among this, the mental pressure has the highest percentage in this case [21].

The need of flying job to the application of coping strategies is subjected to the construction of speed into the related occupation; the application of coping strategies in flight can be effective to some extent the reduction of flight accidents. The number of foreign and domestic studies is certainly limited. Among the similar studies the study of Farkhondehnezhad can be mentioned regarding to the flight attendants and Javaheri's study in relation to the military pilots [21] [22]. Lazarus et al. stated two forms of coping; in the problem-focused coping, the process of change is being roughly emphasized for reducing the stressful environment. The emotional-focused coping emphasize on the application of thoughts or activities making someone vulnerable to the stressful situations [23]. Higgins and Andler categorized the coping strategies into three groups: Task-oriented; Emotionoriented; and Avoidance-oriented [24]. Bilingz and Moos consider the cognitions and behaviors as the skills regarding to the coping strategies being applied by people for evaluating, conducting and balancing the mental pressure [25]. These mentioned theories could be established into micro models and macro theories in the field of job satisfaction. The micro models theories include the theories of needs and cognitive theories working on the environments where the job satisfaction is based on what people bring to their workplace [26]. In this case, the theories of Maslow, McClelland, and equity and self-determination have been discussed.

Maslow's hierarchy of needs, as a theory of human motivation is represented the human needs including needs of physiological, safely, love/belonging, and self-actualization [27].

McClelland identified three motivators that he believed we all have: a need for achievement, a need for affiliation, and a need for power. People will have different characteristics depending on their dominant motivator. According to McClelland, these motivators are learned (which is why this theory is sometimes called the Learned Needs Theory). McClelland says that, regardless of our gender, culture, or age, we all have three motivating drivers, and one of these will be our dominant motivating driver. This dominant motivator is largely dependent on our culture and life experiences [28].

Equity theory is a theory that attempts to explain relational satisfaction in terms of perceptions of fair/unfair distributions of resources within interpersonal relationships. Considered one of the justice theories, equity theory was first developed in 1963 by John Stacey Adams, who asserted that employees seek to maintain equity between the inputs that they bring to a job and the outcomes that they receive from it against the perceived inputs and outcomes of others [29]. The belief is that people value fair treatment which causes them to be motivated to keep the fairness maintained within the relationships of their co-workers and the organization. The structure of 
equity in the workplace is based on the ratio of inputs to outcomes. Inputs are the contributions made by the employee for the organization.

The self-determination theory clarifies that the global cognitive mental needs like competency, independency and relationship that the humans become motivate based on them. The satisfaction of these needs plays a key role in the staffs' well-being. The satisfaction of these needs can increase the well-being and motivation of the whole staffs in every culture. Of course the importance of these needs is different in the whole different fields [30].

The management style of the emotions in work environment plays a key role in the function and job satisfaction [31]. There have been established various reasons for the influence of emotional regulation on job satisfaction; people having more skills in evaluating and regulating their emotions will face with higher levels of job satisfaction. Therefore, the stress-coping skills and organizational commitment are two main factors of determining the job satisfaction issue [11].

There have been many different studies emphasized on the high correlation between the depression, anxiety, physical compliments, unsuitable social performance with job stress, low job support, unsuitable job conditions, hardworking and lack of job security [32]-[35]. Also there is a relationship between the job satisfaction and physical health [36]. It can be stated that people dissatisfied of their job are more disposed to the mental and physical [37]. Lazarus and Folkman, Sandler et al. have emphasized on the relationship of coping skills and physical compliments [23] [38]. Many researchers considered the application of adaptive coping strategies as the most significant factor against the tensioning agents that these can reduce the physical compliments increasing the same physical health in this regard [39]-[42].

Shareh in his researches concluded that there is a relationship between the job tensions and coping skills, inhibition of somatization and job satisfaction; people using coping strategy of problem solving can manage the related tensions easily reaching to high job satisfaction and mental physical health [43]. Due to the fact that the flight personnel are facing with higher catastrophic events, they will feel higher stressful settings making them towards the mental pressures. It seems that the stress coping skills can represent the level of job satisfaction. Due to the mentioned statements, it is tried to response the question whether the pilots and co-pilots job satisfaction can be predicted with the coping skills?

\section{Method}

\subsection{Procedure}

The present study is a descriptive-correlation based research. The statistical population includes the pilots and co-pilots of Tehran Mehrabad Airport in 2012. About 200 pilots and co-pilots participating in re-training classes were randomly taken up in the study. After the related permission from the officials, the permission of participants was asked to complete the related questionnaire form April to Mars of 2012; the related questionnaires were distributed among the samples; then, the related explanations were given to the samples and finally the whole questionnaire were gathered from the same sample. It should be mentioned that the entire responses were completed fulfilled in a secrete atmosphere.

\subsection{Instruments}

Coping skill questionnaire of Moos and Billings: Coping responses questionnaire (CRT) made by Billings and Moos in 1981; this questionnaire includes 32 items and five types of coping strategies including the copingbased on problem-solving (3 items), emotion inhibition (11 items), cognitive evaluation (5 items), somatization inhibition (9 items) and social support seeking (4 items). The scoring is based on 4 degree of Likert scale ranging from 0 to 3 . The degree of reliability is 0.9 for the subscale of the questionnaire in problem solving, 0.65 for emotional inhibition, and 0.68 for cognitive evaluation, 0.90 for somatizational inhibition and 0.90 for the social support seeking, respectively. Also, the reliability coefficient of the questionnaire (test-retest) is obtained 0.79 [44].

Job satisfaction inventory: (JDI): This questionnaire is made in Kernel University by Smith, Kendal and Hulin testing the satisfaction from the related occupation in a five categories [45]. This questionnaire includes 41 questions based on a five scale of Likert being adjusted based on the dimensions of job nature and type with 10 items: supervision with 10 items, staffs with 10 items, promotion with 5 items, salary with 5 items and finally 
the total job satisfaction with a one item [46]. The carried out studies in Iran, the indicator of jobs description has been applied in the research. The reliability of this inventory using internal convergent method (Cronbach alpha) is obtained 0.91 . The internal validity of the job description index using Cronbach alpha method is 0.80 for job nature, 0.89 for supervision, 0.87 for coworkers, 0.90 for promotion and 0.90 for the salary [45]. The reliability of the questionnaire using correlation with Mine Souta scale for total job satisfaction, satisfaction from the work, supervision, salary, promotion and coworker is $42.63,0.25,0.48,0.37,0.31$, respectively [47].

\section{Finding}

The indicators of central tendency and distribution were applied in order to describe the under study variables. The multiple regression analysis method was also applied to analyze the related data. The carried out measurement were given in Table 1 and Table 2.

Based on Table 1, the scores of the participants in job satisfaction tests (and its three subscales: supervisor' satisfaction, coworkers satisfaction and promotion of satisfaction) and coping skills (and its five subscales: problem solving, cognitive evaluation, emotional inhibition, social support and somatization) and other different indices including the mean, standard deviation, skewness and kurtosis (the distributional indices showed that the distribution of the sample groups' scores tend to normal distribution in measured variables).

Hypothesis: Based on the coping skills of problem solving, emotional inhibition, social support and somatization, the job satisfaction of the pilots and co-pilots can be predicted.

As it shown in Table 2, the amount of $\mathrm{R}^{2}$ is 0.149 representing that about $14.9 \%$ of the variation of variables is being represented in relation to the pilots and co-pilots job satisfaction through 5 coping skills variables. The statistics $t$ and the significance levels indicated that among the related subscales, two somatization and emotion inhibition coping skills could negatively predict the job satisfaction.

Table 1. Descriptive indices of total scores in test of job satisfaction (and its three subscales) and coping skills (and its five subscales $)(\mathrm{N}=200)$.

\begin{tabular}{|c|c|c|c|c|c|}
\hline \multirow{2}{*}{ Variable } & \multicolumn{5}{|c|}{ Descriptive indices } \\
\hline & Subscales & Mean & Standard Deviation & Skewness & Kurtosis \\
\hline \multirow[t]{4}{*}{ Job satisfaction } & Satisfaction supervision & 37.67 & 6.26 & -0.312 & -0.413 \\
\hline & Coworkers satisfaction & 36.09 & 5.98 & -0.071 & -0.098 \\
\hline & Promotion satisfaction & 15.32 & 3.00 & -0.233 & 1.176 \\
\hline & Job satisfaction (total score) & 146.74 & 17.73 & 0.028 & -0.392 \\
\hline \multirow[t]{5}{*}{ Coping skills } & Problem solving & 7.51 & 1.34 & 0.866 & 0.243 \\
\hline & Cognitive evaluation & 10.83 & 2.41 & -0.725 & 1.203 \\
\hline & Emotion inhibition & 9.72 & 2.82 & 0.735 & 1.809 \\
\hline & Social support & 6.63 & 1.83 & -0.460 & 0.399 \\
\hline & Somatization & 2.75 & 3.39 & 2.067 & 4.702 \\
\hline
\end{tabular}

Table 2. Summary of regression analysis to predict the job sastisfaction based on five subscales of coping skills $(\mathrm{N}=200)$.

\begin{tabular}{|c|c|c|c|}
\hline \multirow{2}{*}{ Predictors } & \multicolumn{3}{|c|}{ Depended variable: job satisfaction } \\
\hline & Non-standard coefficient & Standard coefficient & $\mathrm{T}$ \\
\hline Constant & 138.30 & - & $14.300^{* *}$ \\
\hline Problem solving & -0.501 & -0.038 & -0.464 \\
\hline Cognitive evalution & 0.823 & 0.112 & 1.386 \\
\hline Emotion inhibition & 0.903 & 0.145 & -1.998 \\
\hline Social support & -0.016 & 0.002 & -0.020 \\
\hline Somatization & -1.950 & -0.374 & $-4.512^{* *}$ \\
\hline
\end{tabular}

$\mathrm{R}=0.368, \mathrm{R}^{2}=0.149$, adjusted $\mathrm{R}^{2}=0.127, \mathrm{~F}=6.753,{ }^{* *} \mathrm{p}<0.01$. 


\section{Discussion}

The findings of the study showed that the total scores of pilots and co-pilots job satisfaction is predicted based on two subscales of coping skills, somatization and emotional inhibition. It should be mentioned that the high score in somatization represents the low physical compliment. In other words, the reduction of physical compliment is coming along with the job satisfaction. The obtained findings of the present study are corresponding with the many researches [11] [12] [20] [22] [48] [49].

People having high coping skills can manage the tensions easily [43] and have more job satisfaction and low complaint. In addition, the findings showed that the more emotional inhibition is coming along with job satisfaction. People applying the effective coping strategies, they will be able to diminish the tensions and their own emotions efficiently [50]. They will have also high adaptation to their environment removing any stressful stimulants at their job atmosphere [48]. Therefore application of the coping skills in sensitive jobs such as piloting should be paid attention potentially.

\section{Conclusion}

Given the importance of secure flight, pilots' mental health and reduce of job stress and improve coping skills in them, must be attention by psychologists. The effective coping methods training workshops should be also achieved in order to reduce the degree of stress of the pilots and co-pilots when facing with critical circumstances. The occupational support, increasing the salary, substituting the collapsed airplanes can also increase the job satisfaction leading to the mental health of the related pilots and co-pilots in this regard. One of the most important limitations of the present study is subjected to the lack of study in controlling the factors of job collapse, job stress and leadership styles.

\section{Acknowledgements}

It is warmly appreciated the whole participated pilots and co-pilots of Mehrabad Airport particularly the Mr. Esmaieeli and Captain Ghasemi that let us conduct the present study.

\section{References}

[1] ShafiAbadi, A. (2011) Guidance and Occupational Consultation and Occupational Selection Theories. 20th Edition, Roshd Publication, Tehran.

[2] Khadivi, A. (2007) An Introduction on the Organizational Behavior in New Millennium. Shayesteh, Tabriz. http://dx.doi.org/10.1016/0030-5073(69)90013-0

[3] Locke, E.A. (1969) What Is Job Satisfaction? Organizational Behavior and Human performance, 4, 309-336.

[4] Selye, H. (1974) Stress without Distress. Lippincott, New York.

[5] Abdolmohammadi, K. (2010) Study of Cellular and Humoral Immune System of Army Pilots in Islamic Republic of Iran. Master's Thesis, University of Army Medical Sciences, New Delhi.

[6] Rahnedjat, A.M. (2009) The Effects of Stress on the Performance of Military Pilots and Flight Personnel and Methods of Stress Control. Proceedings of the Second International Congress of Aerospace Medicine and Subsurface, Army College of Medical Sciences in Iran. http://eprints.ajaums.ac.ir/663/1/HavaFaza_Booklet_NewChanged.page046.pdf

[7] Fletcher,C.E. (2001) Hospital RNs' Job Satisfaction and Dissatisfactions. Journal of Nursing Administration, 31, 324335. http://dx.doi.org/10.1097/00005110-200106000-00011

[8] Rajab-Beigi, M., Amini, M., Partovi, B. and Ghanbarzadeh-Alamdari (2006) Measuring Job Satisfaction of Human Resources in the Public Sector and Its Influencing Factors. Journal of Teaching Humanities Science, 10, 10, 85, 111-130.

[9] Robins, A. (2006) Management of Organizational Behavior (Translated by Parsaieeian, A. and Erabi, M.). 11th Printing, Office of Cultural Researches, Tehran.

[10] Greenberg, J. (2005) Managing Behavior in Organizations.4th Edition, Prentice-Hall, Englewood.

[11] Tang, C. and Cheung, F. (2012) Psychological Capital as between Emotional Labor Burnout, and Job Satisfaction among Moderator School Teachers in China. International Journal of Stress Management, 18, 348-371.

[12] Franklin, O. and Cletus, E. (2011) Motivation and Job Satisfaction in the Nigeria Public Service Problems Issues and Challenges. Journal of Business and Organizational Development, 3, 317-330.

[13] Ahsan, N., Abdullah, Z., Yong Gun Fie, D. and Shah Alam, S. (2009) A Study of Job Stress on Job Satisfaction among University Staff in Malaysia: Empirical Study. European Journal of Social Sciences, 8, 121-131. 
[14] Cullen, J.C., Silverstein, B.A. and Foley, M.P. (2008) Linking Biomechanical Workload and Organizational Practices to Burnout and Satisfaction. Journal of Business and Psychology, 23, 63-71. http://dx.doi.org/10.1007/s10869-008-9079-8

[15] Nirel, N., Shirom, A. and Ismail, S. (2004) The Relationship between Job Overload, Burnout and Job Satisfaction, and the Number of Jobs of Israeli Consultants. Article in Hebrew, 143, 779-784, 840, 839. http://www.ncbi.nlm.nih.gov/pubmed/15603264\#.

[16] Weerasinghe, T.D. and Batagoda, C.K. (2001) Job Stress and Job Satisfaction: A Study of Managerial Employees in Domestic Commercial Banks. Faculty of Commerce and Management Studies, 6, 208-213.

[17] Sutherland, V.J. and Cooper, C.L. (1992) Job Stress, Satisfaction, and Mental Health among General Practitioners before and after Introduction of New Contract. British Medical Journal, 304, 1545-1548.

[18] Khaghanizadeh, M., Ebadi, A., Siratinayyer, M. and Rahmani, M. (2008) The Study of Relationship between Job Stress and Quality of Work Life of Nurses in Military Hospitals. Journal of Military Medicine, 10, 175-184. (in Persian)

[19] Kovacs, M. (2007) Stress and Coping in the Workplace. The Psychologist, 20, 548-550. file:///Users/apple/Desktop/thepsychologist\%5C0907kova.pdf

[20] Sudhaker, C.H. and Gomes, L.A. (2010) Job Stress, Coping Strategies and the Job Quality Index of Nurses Working in Selected Multispeciality Hospitals-Towards Human Resource Development. Journal of the Academy of Hospital Administration, 22, 10-14.

[21] Javaheri, M.R. (2010) Study of Air Crashes on the Mental Health and Function of Pilots. Master Thesis, Azad University, Central Tehran Branch, Tehran.

[22] Farkhondehnezhad, S. (2012) Relationship of Occupational Stress and Occupational Satisfaction and Mental Health among Germany Flight Attendants. Master Thesis, Islamic Azad University, Karaj.

[23] Lazarus, R.S. and Folkman, S. (1984) Stress, Appraisal and Coping. Springer, New York.

[24] Higgins, J.E. and Endler, N. (1995) Coping, Life Stress and Psychological and Somatic Distress. European Journal of Personality, 9, 253-270. http://dx.doi.org/10.1002/per.2410090403

[25] Billings, A.G. and Moos, R.H. (1981) The Role of Coping Resources in Attenuating the Stress of Life Events. Journal of Behavior Medicine, 4, 139-157. http://dx.doi.org/10.1007/BF00844267

[26] Trance, M. (2004) People in Organizations. Translated by Shekarkan, H., 1st Edition, Roshd Publication, Tehran.

[27] Gidenz, A. (2011) The Sociology (Translated by Sabouri, M.K.). Nei Publication, Tehran.

[28] McClelland, D.C. (1984) Motives, Personality, and Society: Selected Papers. Praeger, New York.

[29] Adams, J.S. (1965) Inequity in Social Exchange. Advances in Experimental Social Psychology, 62, 335-343.

[30] Deci, E.L., Ryan, R.M., Gagne, M., Leone, D.R., Usunov, J. and Kornazheva, B.P. (2001) Need Satisfaction, Motivation, and Well-Being in the Work Organizations of a Former Eastern Bloc Country: A Cross-Cultural Study of Self-Determination. Personality and Social Psychology Bulletin, 27, 930-942. http://dx.doi.org/10.1177/0146167201278002

[31] Siarouchi, J., Forgas, J. and Mayer, J. (2003) Emotional Intelligence in Daily Life (Translated by Nouri Emam Zadehei, A. and Nasiri, H. (2005)). Neveshteh Publishing Co, Isfahan.

[32] Kojima, M., Senda, Y., Hayashi, H. and Tokudome, S. (2002) An Example of Psychometric Validation of a Mental Health Questionnaire Used at a Work Place. Journal of Occupational Health, 44, 236-241. http://www.ncbi.nlm.nih.gov/pubmed/12512133\#

[33] Edimansyah, B.A., Rusli, B.N., Naing, L., Mohamed Rusli, B.A., Winn, T. and Tengku Mohamed Ariff, B.R.H. (2008) Self-Perceived Depression, Anxiety, Stress and Their Relationships with Psychosocial Job Factors in Male Automotive Assembly Workers. Industrial Health, 46, 90-100. http://dx.doi.org/10.2486/indhealth.46.90

[34] Goorabi, Kh., Shareh, H., Behpajooh, A. and Keihani, M. (2008) Investigating of Mental Health, Depression and Anxiety in Personnel of National Iranian Oil Company. Research Activity, Shahed Institution, Tehran, 105-305. (in Persian)

[35] Park, K.O. (2007) Social Support for Stress Prevention in Hospital Settings. Perspectives in Public Health, 127, 260264. http://dx.doi.org/10.1177/1466424007084066

[36] Terri, O. (1998) An Exploratory Study of the Influence of Life Management Strategies on Job Satisfaction in a Personal Selling Context. Journal of Youth and Adolescence, 12, 121-139.

[37] Yavarian, R. and Samadi, H. (2003) Study of Teachers' Job Satisfaction and Self-Esteem in Urmia, Khoy and Mahabad Exceptional Schools. The Quarterly Journal of Fundamentals of Mental Health, 5, 21-25. (in Persian)

[38] Sandler, I.N., Braver, S. and Gensheimer, L. (2000) Stress Theory, Research and Action. In: Rappaport, J. and Seid- 
man, E., Eds., Handbook of Community Psychology, Vol, 2, Kluwer Academic/Plenum, New York, 187-213. http://dx.doi.org/10.1007/978-1-4615-4193-6_9

[39] Anderson, P. and Jane-Llopis, E. (2006) Mental Health Promotion and Mental Disorder Prevention across European Member States: A Collection of Country Stories. European Communities, Luxembourg.

[40] Ramehst, M. and Farshad, S. (2004) Study of Life Skills Training Impact on Preventing the Drug Abuse of Students. 2nd Congress of Mental Health in Tehran, Tarbiat Modarres University, Tehran, 3-4 March 2004, 41. http://davary.com/seminars/Second_Seminar_of_Students_mental_health.aspx

[41] Sanaiee, B. (2011) Consulting Techniques and Group Mental Therapy. Bessat Publication, Tehran.

[42] Solomon, Z.T. and Habershaim, N. (2011) Life-Events, Coping Strategies, Social Resources, and Somatic Complaints. Journal of the British Psychological Society, 63, 137-148.

[43] Shareh, H. (2011) Impact of Occupational Tensions, Overcoming Approaches against Tension, Resilience and Mental Health in Occupational Satisfaction of Anastasia Technicians. Journal of Mental Health Techniques, 13, 20-29.

[44] Hosseini-Ghadamghahi, J. (2007) Quality of Social Relations, Stress Events and Overcoming Approaches among Cardiac Patients. Master Thesis, Iranian Medical Sciences University, Iranian Psychiatric Institution, Tehran.

[45] Meraiee, M. (2000) Evaluation of Working People’s Job Satisfaction in Cultural Section of Isfahan, a Research Plan. Organization of Management and Planning of Isfahan, Isfahan.

[46] Gholi, Z. (2006) Evaluation of Relationship between Job Satisfaction and Creation in Rasht Water and Treatment Company. Master Thesis, Al Zahra University, Tehran.

[47] Amirzadeh, M. and Ostovar, S. (2008) Study of Relationship between the Intelligence and Excitement, Job Satisfaction and Organizational Commitment among the Workers of a Private Factory in Shiraz. Journal of New Approach in Educational Management, 2, 23-38.

[48] Rast, S. and Toarani, A. (2012) Evaluation of Employees, Job Satisfaction and Rule of Gender Difference: An Empirical Study at Airline Industry in Iran. International Journal of Business and Social Science, 3, 117-134.

[49] Sundberg, L. and Sandberg, C. (2011) The Relationship between Proactive Coping Skills and Job Satisfaction, Absentecism, Tardiness and Performance. International Journal of Business and Social Science, 2, 33-49.

[50] Sy, T., Tram, S. and O’Hara, L.A. (2006) Relation of Employee and Manager Emotional Intelligence to Job Satisfaction and Performance. Journal of Vocational Behavior, 68, 461-473. http://dx.doi.org/10.1016/j.jvb.2005.10.003 
Scientific Research Publishing (SCIRP) is one of the largest Open Access journal publishers. It is currently publishing more than 200 open access, online, peer-reviewed journals covering a wide range of academic disciplines. SCIRP serves the worldwide academic communities and contributes to the progress and application of science with its publication.

Other selected journals from SCIRP are listed as below. Submit your manuscript to us via either submit@scirp.org or Online Submission Portal.
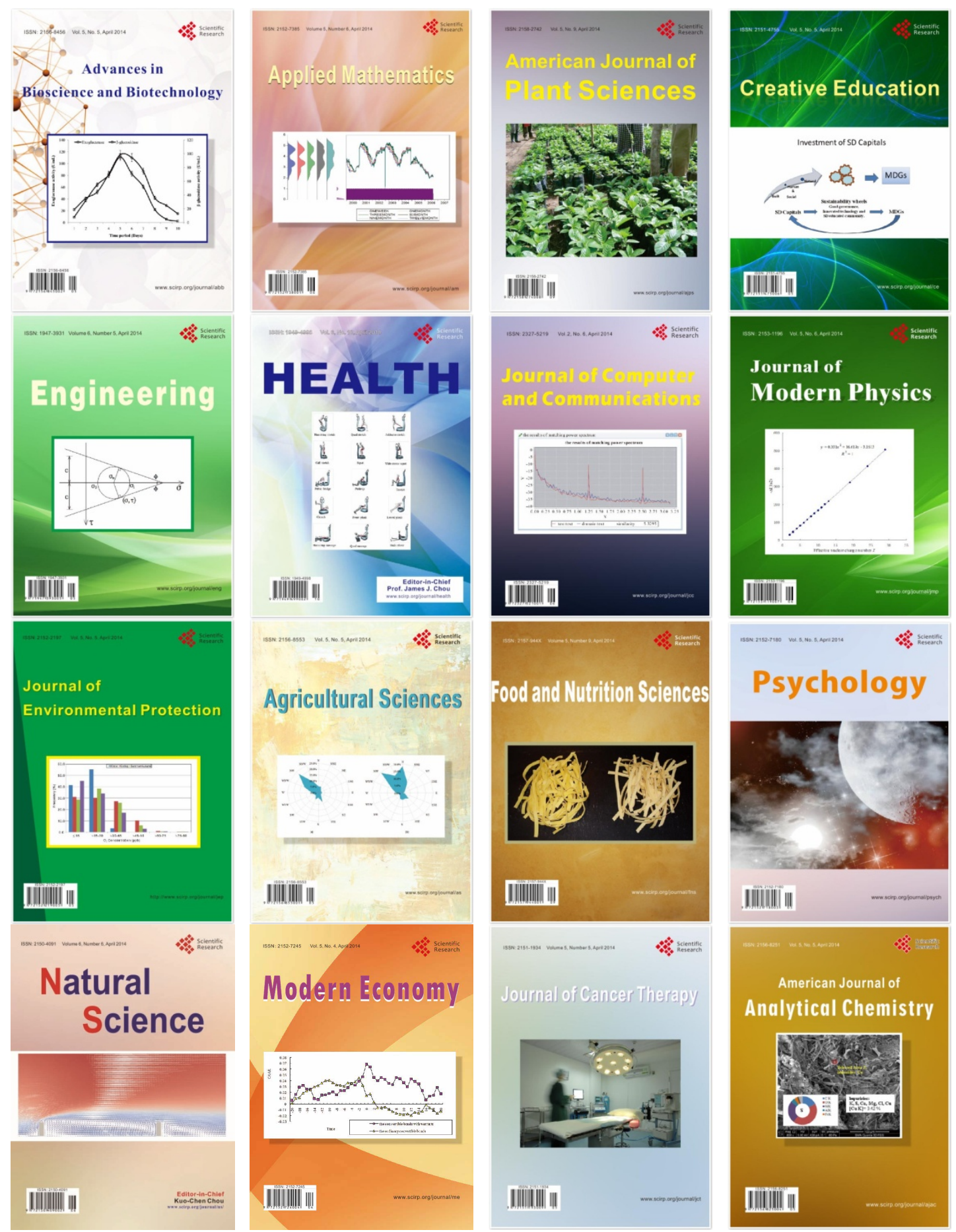